Article

\title{
The Interfacial Microstructure and Mechanical Properties of Diffusion-Bonded Joints of 316L Stainless Steel and the 4J29 Kovar Alloy Using Nickel as an Interlayer
}

\author{
Tingfeng Song ${ }^{1}$, Xiaosong Jiang ${ }^{1}$, , Zhenyi Shao ${ }^{1,2}$, Defeng Mo ${ }^{3}$, Degui Zhu ${ }^{1}$ and \\ Minhao Zhu ${ }^{1}$ \\ 1 School of Materials Science and Engineering, Southwest Jiaotong University, Chengdu 610031, Sichuan, \\ China; tfsong@yeah.net (T.S.); zysao_10227@163.com (Z.S.); dgzhu@home.swjtu.edu.cn (D.Z.); \\ zhuminhao@home.swjtu.edu.cn (M.Z.) \\ 2 Department of Material Engineering, Chengdu Technological University, Chengdu 611730, Sichuan, China \\ 3 Key Laboratory of infrared imaging materials and detectors, Shanghai Institute of Technical Physics, \\ Chinese Academy of Sciences, Shanghai 200083, China; modefeng@163.com \\ * Correspondence: xsjiang@home.swjtu.edu.cn; Tel.: +86-28-8760-0779
}

Academic Editor: Giuseppe Casalino

Received: 28 August 2016; Accepted: 19 October 2016; Published: 3 November 2016

\begin{abstract}
L stainless steel (Fe-18Cr-11Ni) and a Kovar (Fe-29Ni-17Co or 4J29) alloy were diffusion-bonded via vacuum hot-pressing in a temperature range of $850-950{ }^{\circ} \mathrm{C}$ with an interval of $50{ }^{\circ} \mathrm{C}$ for $120 \mathrm{~min}$ and at $900{ }^{\circ} \mathrm{C}$ for 180 and $240 \mathrm{~min}$, under a pressure of $34.66 \mathrm{MPa}$. Interfacial microstructures of diffusion-bonded joints were characterized by optical microscopy (OM), scanning electron microscopy (SEM), X-ray diffraction (XRD), and energy dispersive spectroscopy (EDS). The inter-diffusion of the elements across the diffusion interface was revealed via electron probe microanalysis (EPMA). The mechanical properties of the joints were investigated via micro Vickers hardness and tensile strength. The results show that an Ni interlayer can serve as an effective diffusion barrier for the bonding of 316L stainless steel and the 4J29 Kovar alloy. The composition of the joints was 316L/Ni s.s (Fe-Cr-Ni)/remnant Ni/Ni s.s (Fe-Co-Ni)/4J29. The highest tensile strength of $504.91 \mathrm{MPa}$ with an elongation of $38.75 \%$ was obtained at $900{ }^{\circ} \mathrm{C}$ for $240 \mathrm{~min}$. After the width of nickel solid solution (Fe-Co-Ni) sufficiently increased, failure located at the $4 \mathrm{~J} 29$ side and the fracture surface indicated a ductile nature.
\end{abstract}

Keywords: 316 stainless steel; 4J29 Kovar alloy; nickel; diffusion bonding

\section{Introduction}

316L stainless steel (Fe-18Cr-11Ni) is widely used for its low corrosion rate, which is attributed to its inner chromium oxide region and outer mixed iron-nickel oxide region [1,2]. Kovar (Fe-29Ni-17Co) alloys possess the advantages of low-temperature constant expansion, and thermal expansion properties and a good thermal matching performance similar to $\mathrm{Si}, \mathrm{Ge}$, and glass, thus obtaining wide application in the electronics industry [3-5]. Joining stainless steel and Kovar alloys has been widely done in aerospace, nuclear, and electronic industries for technical and economic reasons [6-8]. However, due to the differences in thermo-mechanical and metallurgical properties, many obstacles to achieving good dissimilar joints have been confronted, such as precipitates, intermetallics, and distortions of the weld interface, which is detrimental to joint properties [1,6-9].

Baghjari et al. [6] investigated the laser welding of AISI 420 stainless steel to a Kovar alloy, and the result showed that sulfur and phosphor were segregated at the austenitic boundary, which led to 
cracks formed in the weld and chromium carbide precipitation formed in the ferrite grain boundary. Mai et al. [10] reported on the welding of a Kovar alloy and steel via laser welding and confirmed that elliptically shaped pores formed during the welding process, and the number and size of these pores could be controlled by the welding speed. Inconel 718 and 316 stainless steel were joined via electron beam melting additive manufacturing technology, and the results showed that precipitates of niobium carbide, and the Laves phase formed in the fusion zone, generally led to solidification cracking [1]. Nekouie et al. [11] reported that the microstructure of dissimilar joints could be controlled by adjusting the specific point energy and beam offset when low carbon steel and austenitic stainless steel were welded via laser welding. Wu et al. [12] conducted laser welding between ferritic stainless steel and carbon steel. Lath martensite, upper bainite and widmanstatten structure ferrite were formed in the weld bead. A tensile strength similar to a base metal was achieved, and the fracture position located at the carbon steel base metal were far from the weld bead. Verena et al. [13] investigated the microstructure and the properties of dissimilar joints between high temperature steels PM91 and PM2000 welded via electron beam. Precipitation of an Al phase and the formation of a soft dendritic microstructure in the fusion were attributed to a worse performance. In order to further obtain a high strength and high stability dissimilar joints, a filler material that usually possessed good plasticity or an intermediary coefficient of thermal expansion between parent materials was adopted [14-16]. In this context, nickel was considered a suitable intermediate material because the thermal expansion coefficient of nickel was situated between 316 stainless steel and the 4J29 Kovar alloy, and other suitable properties, such as density, melting point, and crystal type, were similar to them. Wang et al. [17] employed a nickel-phosphorus alloy as an interlayer and achieved a good connection between the Kovar alloy and low-carbon low-alloy steel by using parallel seam welding. Sathiskumar et al. [18] studied a dissimilar joint between pulse-plated nickel and Inconel 718 manufactured via electron beam welding. The grain structure, sizes, orientation, and grain boundary characteristic distribution of the weld seam were investigated to reveal the influence of hydrogen induced cold cracking. Precipitated secondary carbides were observed on the intergranular and intragranular $\gamma$ matrix. Madhusudhan et al. [19] applied nickel as an interlayer to connect maraging steel and low alloy steel via friction welding and revealed that nickel could be an effective barrier for the diffusion of elements such as carbon and manganese, and ductile fracture, higher tensile strength, and higher elongation was obtained. Compared with fusion welding, diffusion welding is a near net shape forming process and more suitable for joining dissimilar materials. It is a kind of welding method where the contact surface achieves porosity closure via creep and diffusion under high temperature and certain pressure [20-22].

In this work, efforts were made to accomplish the solid state diffusion bonding of 316 stainless steel and the 4J29 Kovar alloy using pure nickel as an interlayer. The effect of a nickel interlayer at different temperatures and bonding times was investigated. The research focused on the evolution of the interface microstructure, element diffusion, and the bond strength of joints.

\section{Materials and Methods}

\subsection{Materials and Processing Parameters}

The chemical compositions and physical properties of 316 stainless steel and the 4J29 Kovar alloy are presented in Tables 1 and 2, respectively. Cylindrical specimens with a $30 \mathrm{~mm}$ diameter and a $25 \mathrm{~mm}$ length were machined from the base metals. A pure nickel $(99.9 \mathrm{wt}$. \%) interlayer with a thickness of $70 \mu \mathrm{m}$ was used as an intermediate material. Prior to bonding, the grinding surfaces were cleaned in an ultrasonic bath containing acetone, cleaned by ethyl alcohol, and dried in air. The experiments were conducted in a temperature range of $850-950{ }^{\circ} \mathrm{C}$ with an interval of $50{ }^{\circ} \mathrm{C}$, a bonding time of $120 \mathrm{~min}$, and at $900{ }^{\circ} \mathrm{C}$ with a bonding time of $120 \mathrm{~min}, 180 \mathrm{~min}$, and $240 \mathrm{~min}$ in (1-6) $\times 10^{-1}$ Pa vacuum. $2.5 \mathrm{~T}$ (34.66 MPa) uniaxial pressure was applied via hot pressing. During processing, heating was started at a constant rate of $10^{\circ} \mathrm{C} / \mathrm{min}$; after the joining operation, the furnace was cooled at a rate of $5{ }^{\circ} \mathrm{C} / \mathrm{min}$ to $600^{\circ} \mathrm{C}$ and then naturally cooled to room temperature. 
Table 1. Chemical composition of base metals (wt. \%).

\begin{tabular}{ccccccccccc}
\hline Mn & Si & C & Fe & Co & Ni & Cr & S & P & Mo & Alloy \\
\hline 2.00 & 1.00 & 0.03 & Bal. & - & 11.05 & 18.17 & 0.03 & 0.04 & 2.00 & $316 \mathrm{~L}$ \\
0.4 & 0.2 & 0.02 & Bal. & 17.17 & 28.67 & - & 0.02 & 0.02 & - & $4 \mathrm{~J} 29$ \\
\hline
\end{tabular}

Table 2. Physical properties of base metals (wt. \%).

\begin{tabular}{ccccc}
\hline Alloy & Density $\left(\mathbf{g} / \mathbf{c m}^{\mathbf{3}}\right)$ & Melting Point $\left({ }^{\circ} \mathbf{C}\right)$ & $\begin{array}{c}\text { Expansion Coefficient } \\
\left(\mathbf{1 0}^{-\mathbf{6}} \mathbf{K}^{-\mathbf{1}}\right)\end{array}$ & $\begin{array}{c}\text { Ultimate Tensile Strength } \\
(\mathbf{M P a})\end{array}$ \\
\hline 316L & 8.9 & 1375 & 16 & 573 \\
4J29 & 8.1 & 1460 & 4.7 & 580 \\
\hline
\end{tabular}

\subsection{Interface Microstructure Characterization}

The bonded joints were cut longitudinally, grounded, polished, and etched with a separate reagent for metallographic observations. Stainless steel sides were etched by aqua regia. Kovar alloy sides were etched by a mixture of $2.5 \mathrm{~g}$ of $\mathrm{CuCl}_{2}, 50 \mathrm{~mL}$ of ethyl alcohol, and $50 \mathrm{~mL}$ of $\mathrm{HCl}$. The change in microstructure owing to diffusion was revealed via light microscopy (AxioCam MRc 5, ZEISS, Wetzlar, Germany). Line scanning of the interface was carried out with a scanning electron microscope (SEM, JEOL Ltd., Tokyo, Japan JSM-7001F at $15 \mathrm{kV}$ ) equipped with an X-ray energy-dispersive spectrometer (EDS, JEOL Ltd., Tokyo, Japan) and an electron probe microanalyzer (EPMA, JEOL Ltd., Tokyo, Japan JXA-8530F field-emission hyperprobe at $15 \mathrm{kV}$ ) for elemental mapping using a wavelength-dispersive spectrometer (WDS, JEOL Ltd., Tokyo, Japan) to evaluate the diffusion of elements at the interface.

\subsection{Evaluation of Mechanical Properties}

Tensile properties of the transition joints were evaluated using a microcomputer-controlled electronic universal testing machine (WDW-3100, Rui Machinery, Changchong, China) at a loading rate of $0.5 \mathrm{~mm} / \mathrm{min}$ at room temperature. The hardness measurements were carried out using a micro-Vickers hardness tester (HXD-100TM/LCD, TaiMing, Shanghai, China). The test load was $200 \mathrm{gf}$, and the dwell time was $15 \mathrm{~s}$.

\section{Result and Discussion}

\subsection{Optical Microstructure}

Figure 1 shows an optical micrograph of the diffusion-bonded joints between the 316 stainless steel and the 4J29 Kovar alloy with $\mathrm{Ni}$ as an interlayer for $120 \mathrm{~min}$ at different temperatures. Sound diffusion interfaces were achieved, and interface lines were clearly visible. The microstructure of 316L stainless steel is equiaxed grain, and the grain size remains unchanged. However, the grain size of the 4J29 side with equiaxed austenitic grains and some twins gradually increased. Via the quantitative metallography method, the average grain size of the Kovar alloy bonded at $850{ }^{\circ} \mathrm{C}, 900{ }^{\circ} \mathrm{C}$, and $950{ }^{\circ} \mathrm{C}$ was about $24 \mu \mathrm{m}, 37 \mu \mathrm{m}$, and $69 \mu \mathrm{m}$, respectively. It has been illustrated that the thickness of the diffusion layer between the 316 stainless steel and the $\mathrm{Ni}$ interlayer (Ni-316L) was apparently extended, with a temperature varying from 850 to $950{ }^{\circ} \mathrm{C}$. According to Figure 2, it was about 4-8 $\mu \mathrm{m}$ at $850{ }^{\circ} \mathrm{C}, 6-9 \mu \mathrm{m}$ at $900{ }^{\circ} \mathrm{C}$, and $8-14 \mu \mathrm{m}$ at $950{ }^{\circ} \mathrm{C}$, but that of the $4 \mathrm{~J} 29$ Kovar alloy and the Ni interlayer side (Ni-4J29) cannot be seen obviously, as shown in Figure 3. The influence of the diffusion time on the microstructure of the joints is shown in Figure 2; as bonding time increases, the width of the diffusion layer at the joint interface of 316 stainless steel and the Ni interlayer simultaneously extends. From Figures 1 and 2, it can be seen that the diffusion layer was not uniformly and smoothly distributed, which is attributed to some untight contact between the surface of the base metals, and a zigzagged interface was formed. 

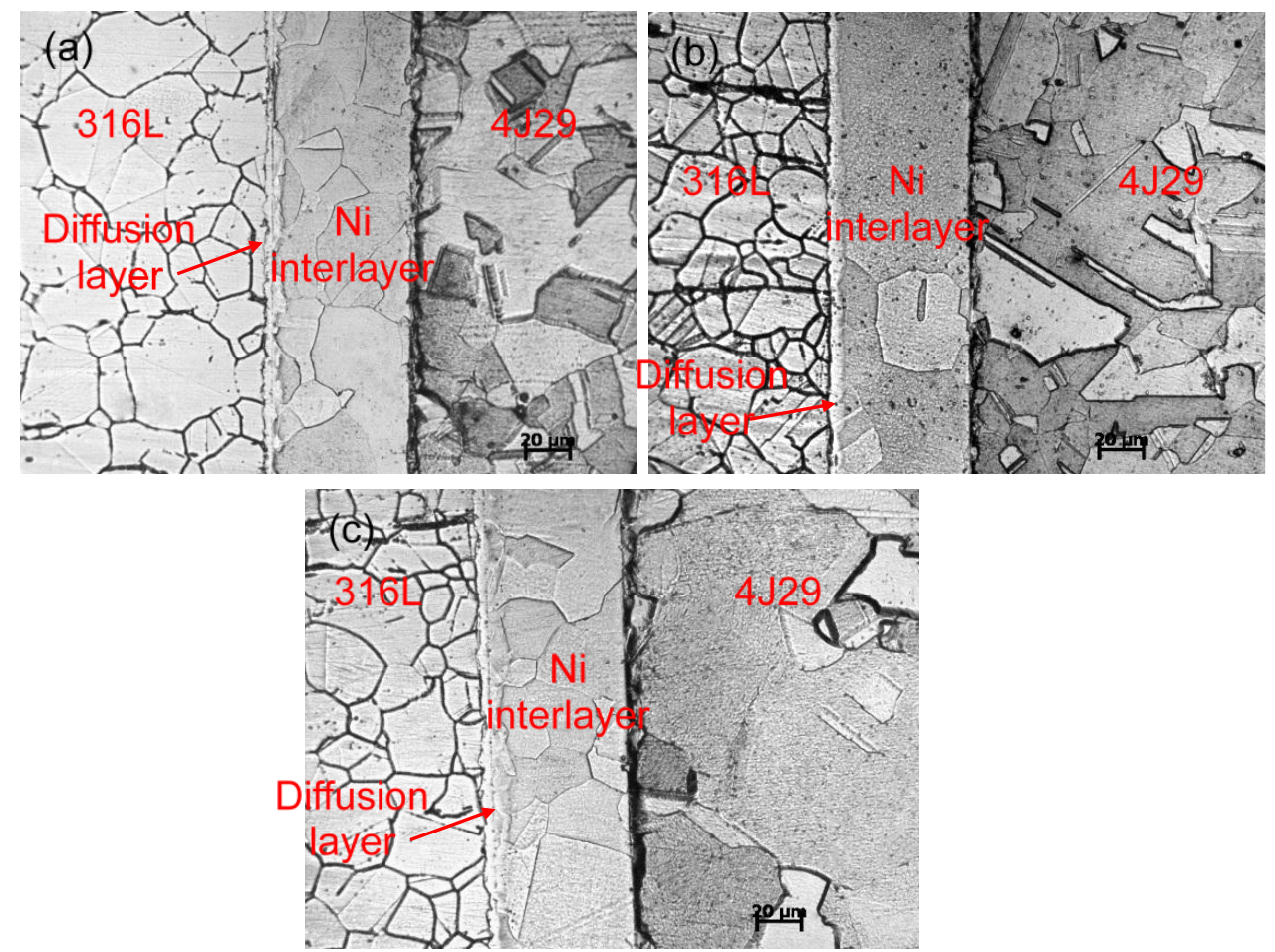

Figure 1. Optical micrograph of diffusion-bonded joints for $120 \mathrm{~min}$ at (a) $850{ }^{\circ} \mathrm{C},(\mathbf{b}) 900{ }^{\circ} \mathrm{C}$, and $(\mathbf{c}) 950{ }^{\circ} \mathrm{C}$.

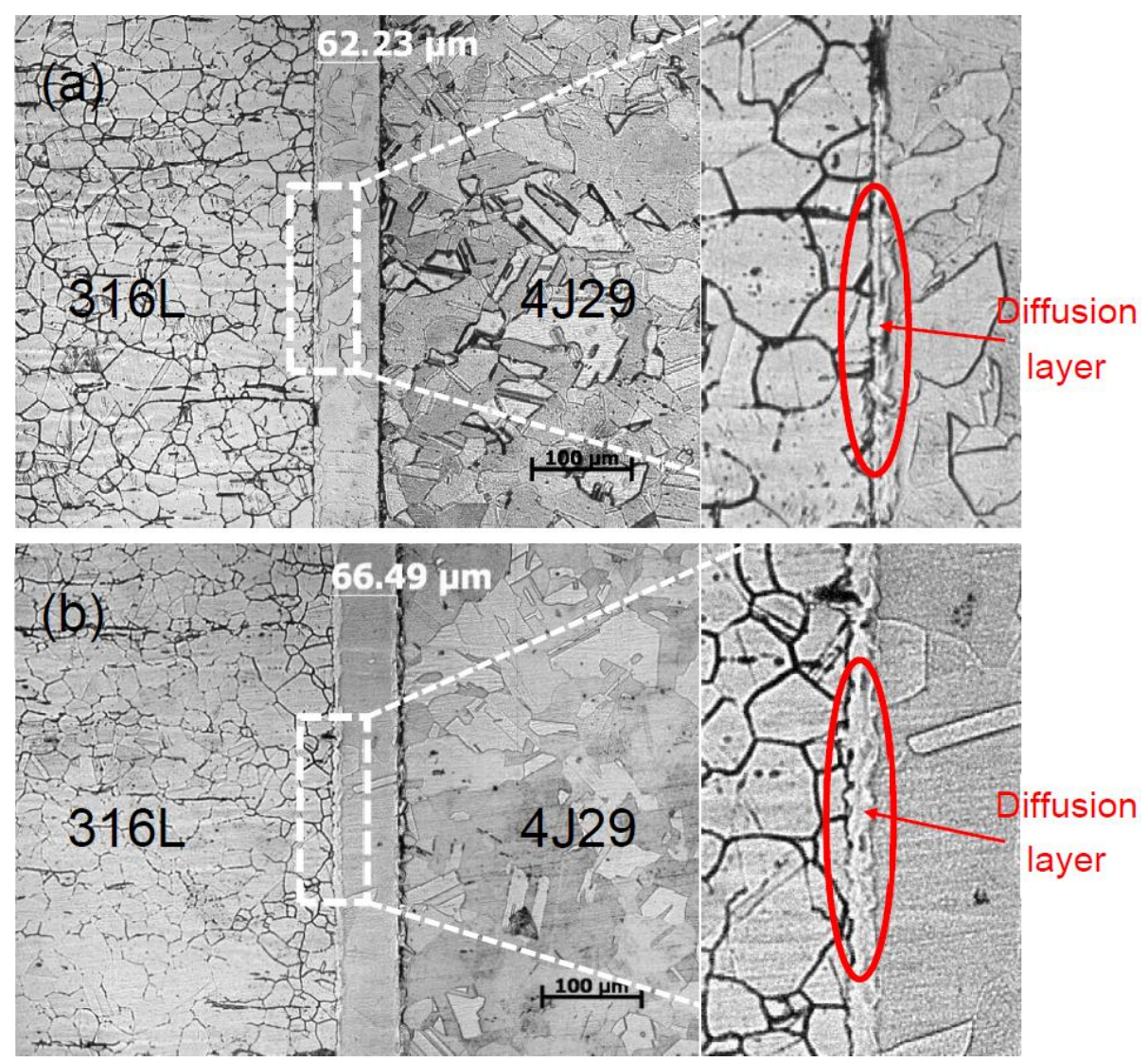

Figure 2. Optical micrograph of diffusion-bonded joints at $900{ }^{\circ} \mathrm{C}$ for (a) $180 \mathrm{~min}$ and (b) $240 \mathrm{~min}$. 


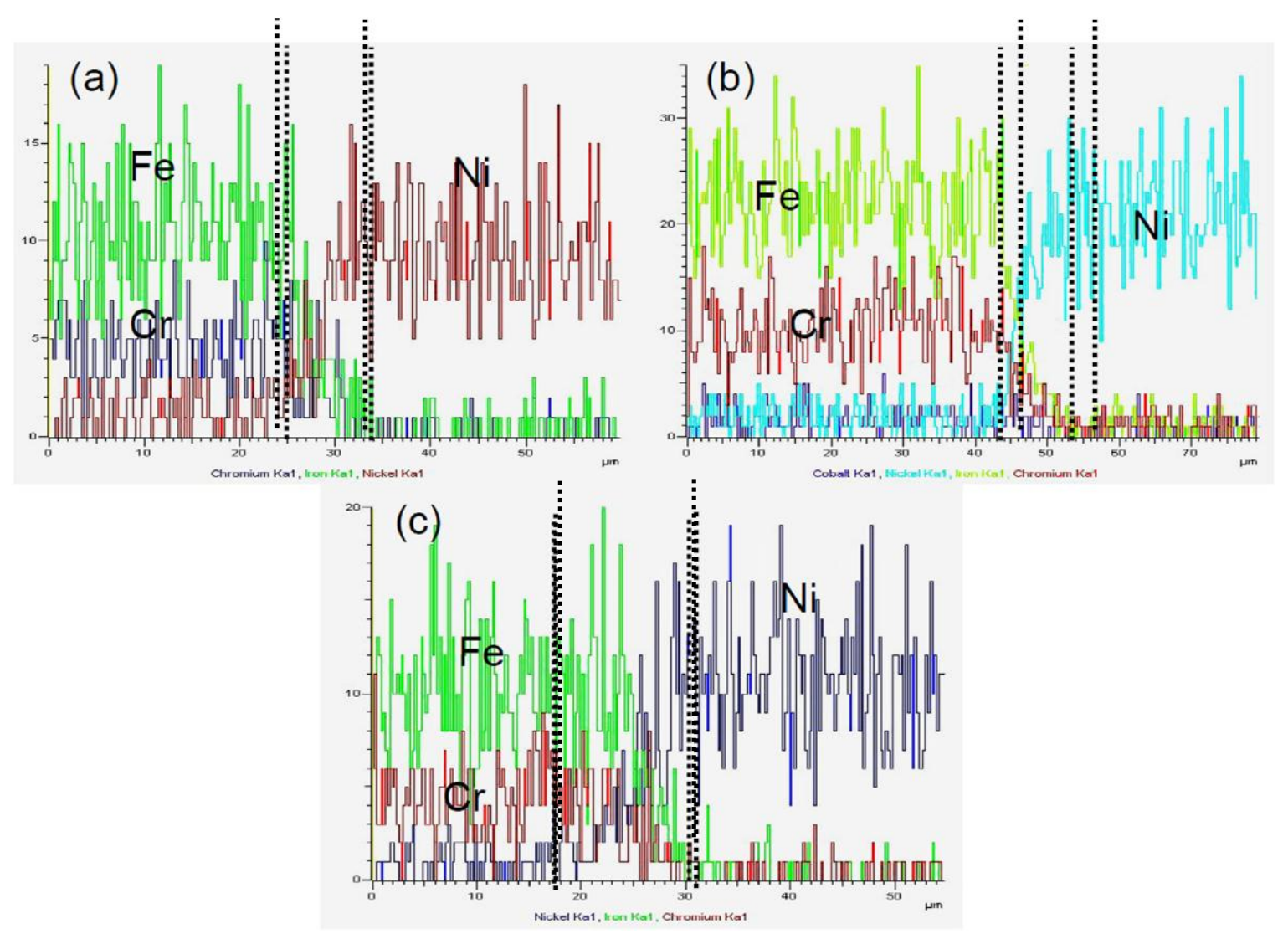

Figure 3. Concentration profiles of elements at the interface of $\mathrm{Ni}$ interlayer and the 316 side bonded at (a) $850{ }^{\circ} \mathrm{C}$, (b) $900{ }^{\circ} \mathrm{C}$, and (c) $950^{\circ} \mathrm{C}$ for $120 \mathrm{~min}$.

\subsection{Element Distribution}

The concentration profiles of the elements, namely, $\mathrm{Fe}, \mathrm{Cr}$, and $\mathrm{Ni}$, at the interface of the $\mathrm{Ni}$ interlayer and the 316L side bonded at different temperatures were measured with EDS line scans, as shown in Figure 3a-c. It can be clearly seen that, as bonding temperature varied from 850 to $950^{\circ} \mathrm{C}$, the width of the diffusion area had a tendency to increase, as shown between the dotted lines. Moreover, the element concentration gradually decreased, and no apparent element aggregation was found at the interface of the Ni-316L side, which means that the intermetallic compounds did not form in the interface. The diffusion bonding of joints mainly depends on the formation of the nickel solid solution of $\mathrm{Fe}-\mathrm{Cr}-\mathrm{Ni}$, and this is confirmed by the XRD measurements.

Figure $4 \mathrm{a}-\mathrm{c}$ presents the concentration profiles of the elements at the interface of the Ni interlayer and the $4 \mathrm{~J} 29$ side bonded at $850{ }^{\circ} \mathrm{C}, 900^{\circ} \mathrm{C}$, and $950^{\circ} \mathrm{C}$ for $120 \mathrm{~min}$. The concentration of $\mathrm{Fe}, \mathrm{Co}$, and Ni at the interface markedly declined. By comparison, the width of the diffusion layers did not evidently change as temperature increased, in accordance with metallurgical research. The different widths of the diffusion layers between the Ni-316L side and the Ni-4J29 side is partly attributed to the different grain sizes of the parent materials. The fine grains of the 316L stainless steel side possessed more grain boundary than the coarse grains of the 4J29 Kovar alloy side, which benefits the diffusion of atoms [23]. Thus, wider diffusion layers were obtained at the Ni-316L side. 


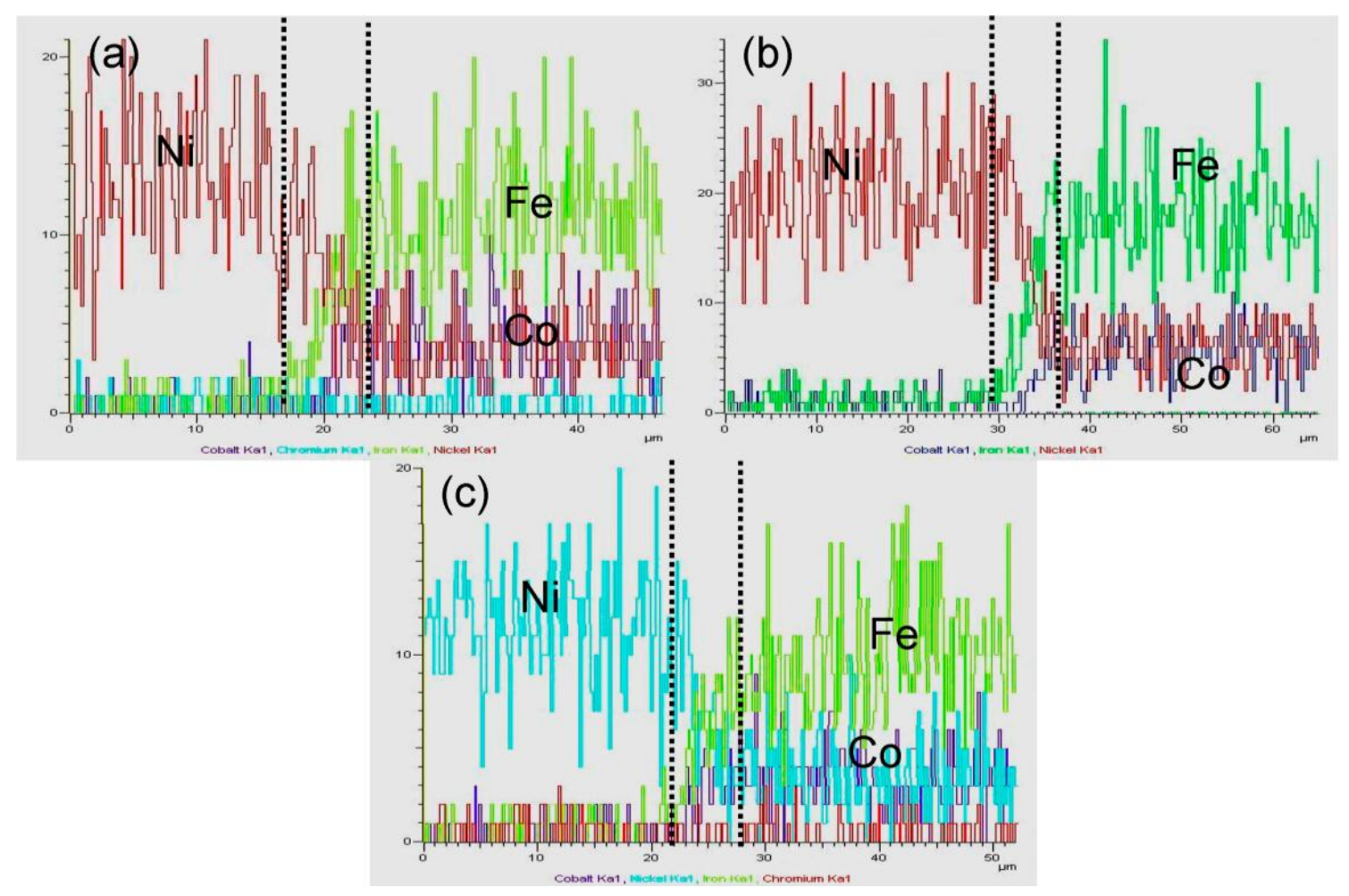

Figure 4. Concentration profiles of elements at the interface of the Ni interlayer and the 4J29 side bonded at (a) $850{ }^{\circ} \mathrm{C}$, (b) $900{ }^{\circ} \mathrm{C}$, and (c) $950^{\circ} \mathrm{C}$ for $120 \mathrm{~min}$.

Figure 5 shows the EPMA analysis of the 316L stainless steel and $4 \mathrm{~J} 29$ joint interface bonded at $950{ }^{\circ} \mathrm{C}$, which displays the diffusion of elements at the interface via elemental maps. Different areas in Figure 5a were detected. It can be seen in Figure $5 \mathrm{~b}$ that the Ni of the interlayer diffused into both 4J29 and 316L sides. However, the extent of Ni into the 316L side was greater than that into the 4J29 side, which was due to a greater difference in the concentration of $\mathrm{Ni}$ between the Ni interlayer and the 316L stainless steel. The Co element of the $4 \mathrm{~J} 29$ did not present evident diffusion into the $\mathrm{Ni}$ interlayer, as shown in Figure 5c, which may be attributed to a higher activation energy for diffusion. The diffusion extent of Fe at the $4 \mathrm{~J} 29$ and 316L side into the Ni interlayer is revealed in Figure $5 \mathrm{~d}$. By comparison, Fe of the 316L side diffused further into the Ni interlayer than that of the 4J29 side due to a higher concentration. Moreover, $\mathrm{Cr}$ diffused into the Ni interlayer is further than that of $\mathrm{Co}$, and both $\mathrm{Fe}$ and $\mathrm{Cr}$ promoted a wider diffusion layer of the 316L side than the $4 \mathrm{~J} 29$ side. Figure $5 \mathrm{e}-\mathrm{f}$ shows the concentration of $\mathrm{Cr}$ and $\mathrm{C}$ in the same position, which shows the phase of chromium carbide at the 316L side, as shown in [6]. According to the element composition of the $\mathrm{Ni}$ interlayer and the $4 \mathrm{~J} 29$ side, the microstructure of the interface was a nickel solid solution of $\mathrm{Fe}-\mathrm{Co}-\mathrm{Ni}$. 

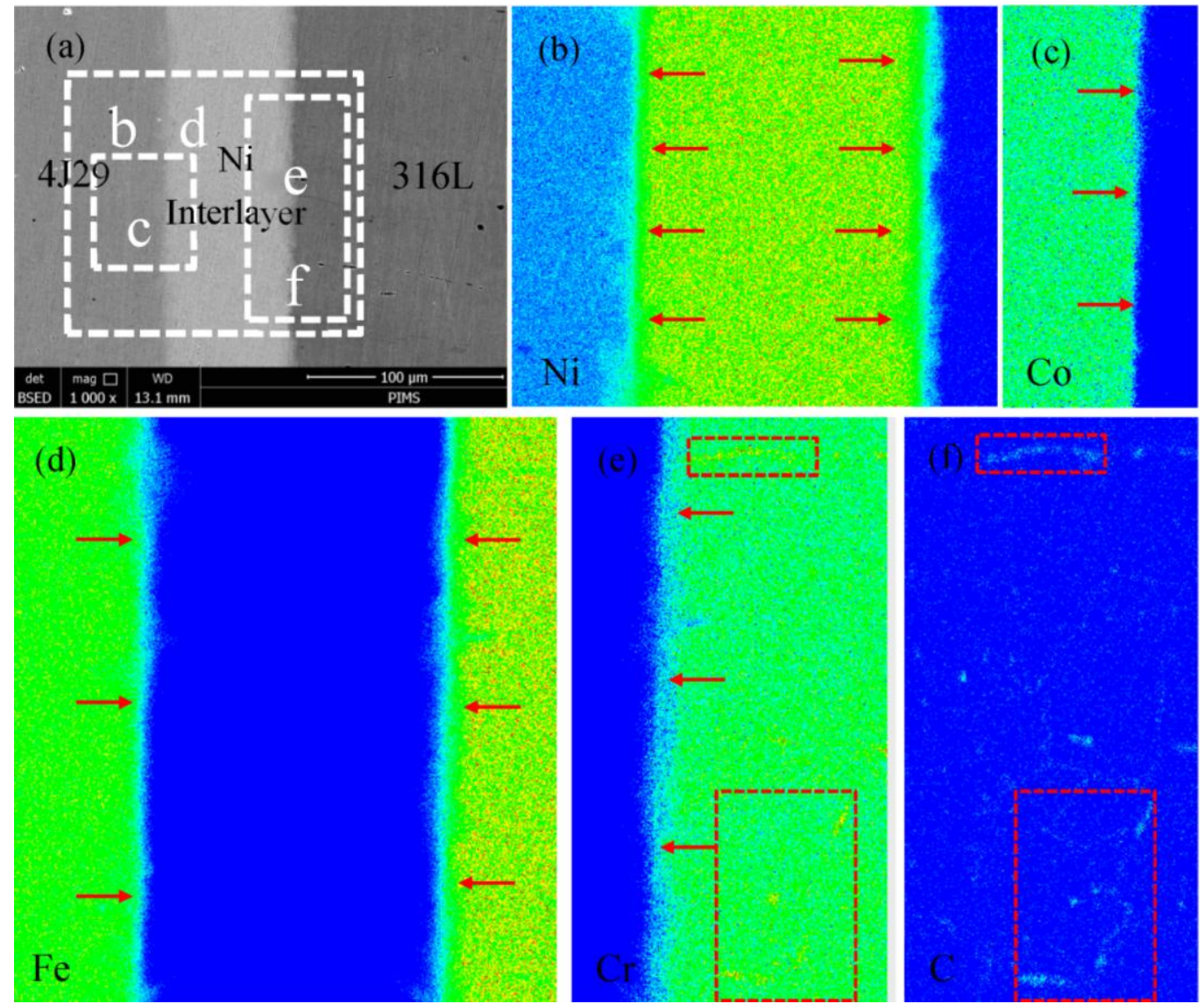

Figure 5. Concentration profiles from electron probe microanalysis (EPMA) analysis of (a) back-scattered electron (BSE) image and elements (b) $\mathrm{Ni},(\mathbf{c}) \mathrm{Co},(\mathbf{d}) \mathrm{Fe},(\mathbf{e}) \mathrm{Cr}$, and (f) C.

\subsection{Diffusion Coefficient}

According to Fick's second law, in infinite length diffusion, the relationship between elemental concentration and distance from the interface can be written as follows:

$$
\frac{\partial C}{\partial t}=D \frac{\partial^{2} C}{\partial x^{2}}
$$

When the boundary conditions are conformed, the solution of Equation (1) can be written as follows:

$$
C(x, t)=\frac{C_{1}+C_{2}}{2}+\frac{C_{1}-C_{2}}{2} \operatorname{erf}\left(\frac{x}{2 \sqrt{D t}}\right)
$$

where $C_{1}$ and $C_{2}$ are initial concentrations of the element in both materials, $x$ is the distance from the interface, $t$ is diffusion time, and $D$ is diffusion coefficient [24]. Based on the element concentration of a certain distance from the interface, the diffusion coefficient can be calculated by Equation (2).

Table 3 exhibits the diffusion coefficients of $\mathrm{Ni}$ on both sides of $\mathrm{Ni}-316 \mathrm{~L}$ and $\mathrm{Ni}-4 \mathrm{~J} 29$ at temperatures varying from $850{ }^{\circ} \mathrm{C}$ to $950{ }^{\circ} \mathrm{C}$. The diffusion coefficients of $\mathrm{Ni}$ into both sides gradually increased as temperature increased, which conforms to the regulation of Arrhenius Equation (3), but the increase of the 316L side was more obvious. The calculated diffusion coefficients of Ni into the $316 \mathrm{~L}$ and $4 \mathrm{~J} 29$ sides were smaller than the reported literature value, $1.15 \times 10^{-15} \mathrm{~m}^{2} / \mathrm{s}$ at $850^{\circ} \mathrm{C}$ into pure iron [23]. The lower values in the current work are attributed to a higher concentration of $\mathrm{Ni}$ in the 316L stainless steel and the 4J29 Kovar alloy compared with that of pure iron. In addition, the presence of greater amounts of alloying elements such as $\mathrm{Cr}$, Si, Mo and Mn in 316L stainless steel and $\mathrm{Co}, \mathrm{Si}$, and $\mathrm{Mn}$ in the 4J29 Kovar alloy may cause a low diffusion of nickel due to the change in 
crystal structure. This result also confirms that the concentration gradient oriented is more obvious than the chemical activation on the diffusion of Ni across the interface. The Arrhenius equation can be written as Equation (4):

$$
\begin{aligned}
& D=D_{0} \exp \left(-\frac{Q}{R T}\right) \\
& \ln D=\ln D_{0}-\frac{Q}{R T}
\end{aligned}
$$

where $D_{0}$ is the diffusion constant $\left(\mathrm{m}^{2} / \mathrm{s}\right), Q$ is the activation energy for diffusion $(\mathrm{kJ} / \mathrm{mol}), R$ is the real gas constant $(8.314 \mathrm{~J} / \mathrm{mol})$, and $T$ is the bonding temperature $(\mathrm{K})$. Based on Equation (4), the activation energy for the diffusion of $\mathrm{Ni}$ can be calculated for the guidance of the parameter controlling the extent of diffusion. Curves of the diffusion coefficient vs. the temperature are exhibited in Figure 6. According to the slope of the plot in Figure $6 \mathrm{a}, \mathrm{b}$, the activation energy for the diffusion of Ni into 316L and $4 \mathrm{~J} 29$ is $173.68 \mathrm{~kJ} / \mathrm{mol}$ and $133.27 \mathrm{~kJ} / \mathrm{mol}$, respectively.

Table 3. Diffusion coefficients of Ni into the 316L and 4J29 sides.

\begin{tabular}{ccc}
\hline \multirow{2}{*}{ Sample $\left({ }^{\circ} \mathbf{C}, \mathbf{m i n}\right)$} & Diffusion of Ni into $\mathbf{3 1 6 L}$ & Diffusion of Ni into 4J29 \\
\cline { 2 - 3 } & $\left(\times \mathbf{1 0}^{-\mathbf{1 6}} \mathbf{~ m}^{\mathbf{2}} / \mathbf{s}\right)$ & $\left(\times \mathbf{1 0}^{-\mathbf{1 6}} \mathbf{~ m}^{\mathbf{2}} \mathbf{s}\right)$ \\
\hline 850,120 & 2.03 & 2.37 \\
900,120 & 6.62 & 5.60 \\
950,120 & 9.23 & 7.58 \\
\hline
\end{tabular}
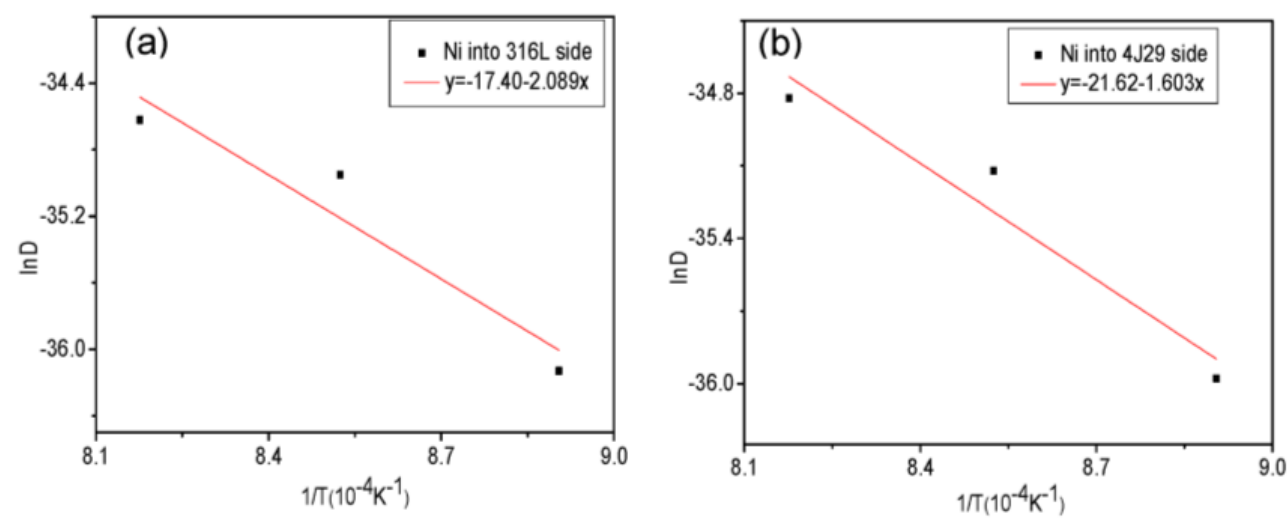

Figure 6. Curves of diffusion coefficient vs. temperature: (a) Ni into 316L side; (b) Ni into 4J29 side.

\subsection{XRD Analysis}

X-ray diffraction patterns of the parent materials and the diffusion layer on both sides of the bonded joints at $950{ }^{\circ} \mathrm{C}$ are shown in Figure 7. The microstructure of $4 \mathrm{~J} 29$ consists of the austenite phase $(\gamma-\mathrm{Fe})$ and the ferrite phase $(\alpha-\mathrm{Fe})$. It was found that, compared with the parent material of $4 \mathrm{~J} 29$, more $\gamma$-Fe was formed owing to the existence of more $\gamma$-stabilizing $\mathrm{Ni}$ in the Ni-4J29 diffusion layer. Moreover, a solid solution of nickel (Ni s.s) was observed on the 4J29 and Ni interlayer sides, which was due to the high concentration of $\mathrm{Ni}$ and the sufficient solid solubility of $\mathrm{Ni}, \mathrm{Fe}$, and $\mathrm{Co}$. On the other hand, a Ni s.s was also formed on the 316L and Ni interlayer sides, which promoted a good bond between the 316L stainless steel and the Ni interlayer. Compared with other literature reports $[1,6,12]$, there has been no formation of the detrimental phase and segregation of sulfur and phosphor to result in hot cracks at interfaces. It is concluded here that a Ni interlayer can serve as an effective diffusion barrier for the bonding of 316L and 4J29. The composition of the joints was 316L/Ni s.s (Fe-Cr-Ni)/ remnant Ni/Ni s.s (Fe-Co-Ni)/4J29. 


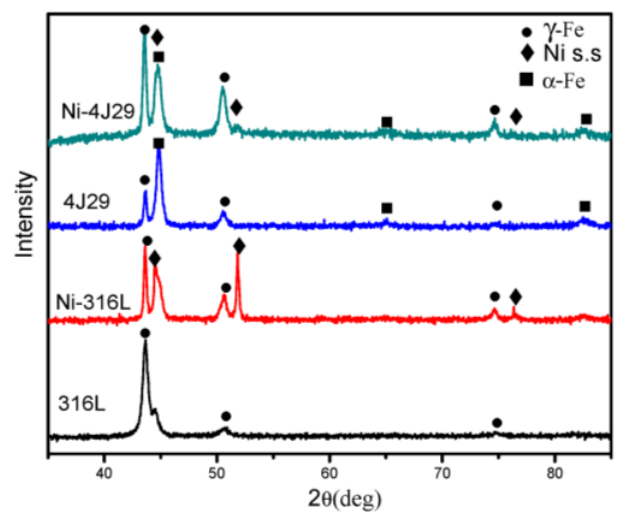

Figure 7. X-ray diffraction patterns of the parent materials and the diffusion layer on both sides of the bonded joints at $950{ }^{\circ} \mathrm{C}$.

\subsection{Hardness}

Figure 8 shows the variation in micro-hardness of the bonded joint at different parameters. The hardness of the interface distinctly decreased on both sides of the 316L stainless steel and the 4J29 Kovar alloy, and the lowest hardness appeared at the Ni interlayer because of its excellent plasticity, which is a benefit for releasing the stress derived from the significant difference of expansion coefficients between parent metals. By comparison, the hardness distribution and the tendency of the bonded interface did not apparently change with parameters. It was observed that the hardness of the 316L side was a small reduction, which may be due to the aging and tempering treatment of the austenitic stainless steel at $900{ }^{\circ} \mathrm{C}$ for $240 \mathrm{~min}$.

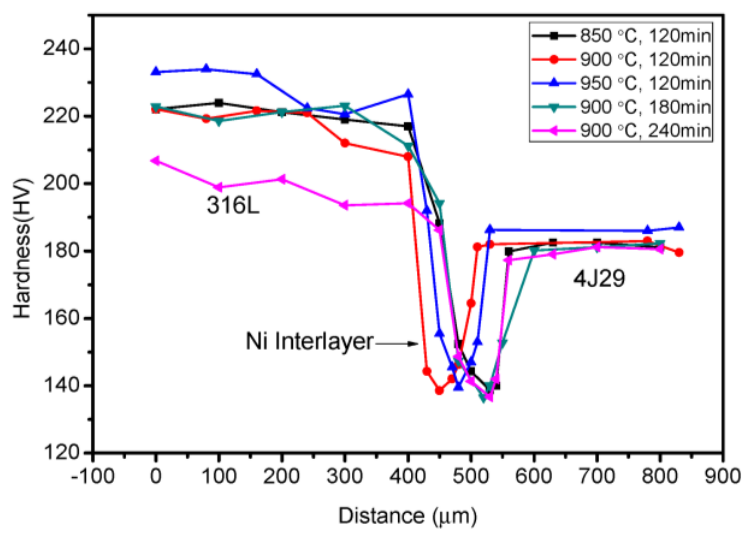

Figure 8. Micro-hardness of 316L stainless steel and the 4J29 Kovar alloy, diffusion-bonded with nickel as an interlayer at different parameters.

\subsection{Tensile Strength and Fracture Analysis}

Variation in the mechanical properties of the bonded joints processed at different parameters is shown in Table 4 and Figure 9. At $850{ }^{\circ} \mathrm{C}$ and $900{ }^{\circ} \mathrm{C}$ for $120 \mathrm{~min}$, some joints were fractured at the interface on account of the insufficient creep deformation to form a compact diffusion layer. When the joints were bonded for $120 \mathrm{~min}$, tensile strength gradually increased as temperature increased. At the same time, the stability of the joints significantly improved, as shown in Figure 9a, which was due to a more sufficient diffusion and bonding between the parent metals and the Ni interlayer. When the joints were processed at $900{ }^{\circ} \mathrm{C}$, the mechanical properties rarely changed after heat preservation beyond $180 \mathrm{~min}$, which means that the width of the diffusion layer was enough to form an excellent joint. Moreover, the highest tensile strength of $504.91 \mathrm{MPa}$ with an elongation of $38.75 \%$ was obtained at $900{ }^{\circ} \mathrm{C}$ for $240 \mathrm{~min}$. 
Table 4. Mechanical properties of 316L stainless steel and the 4J29 Kovar alloy with Ni as an interlayer bonded at different conditions.

\begin{tabular}{cccc}
\hline Sample $\left({ }^{\circ} \mathbf{C}\right.$, min) & Ultimate Tensile Strength (MPa) & Elongation (\%) & Failure Location \\
\hline 850,120 & 215.86 & 6 & Interface \\
900,120 & 451.99 & 25.55 & Interface $/ 4 \mathrm{~J} 29$ side \\
950,120 & 490.62 & 31.25 & $4 \mathrm{~J} 29$ side \\
900,180 & 501.84 & 38.75 & $4 \mathrm{~J} 29$ side \\
900,240 & 504.91 & 38.75 & $4 \mathrm{~J} 29$ side \\
\hline
\end{tabular}
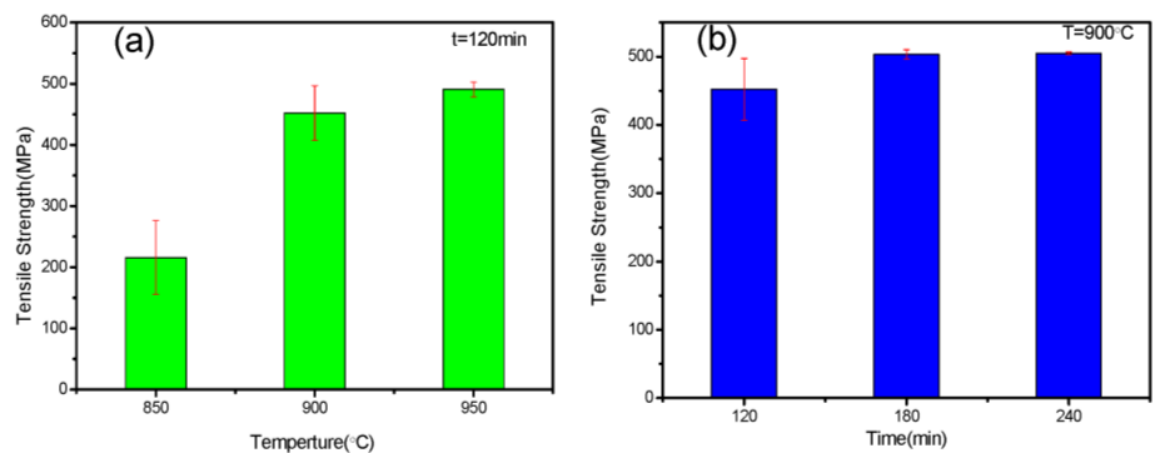

Figure 9. Mechanical properties of diffusion-bonded joints processed at different temperatures (a) and times (b).

Fracture morphologies on the 4J29 Kovar alloy side of the diffusion-bonded joints at different temperatures are shown in Figure 10. At a lower bonding temperature of $850^{\circ} \mathrm{C}$, a large amount of the terrace area was presented on the fracture surface, as shown in Figure 10a. According to EDS analysis, these areas were mainly not well bonded to the Kovar alloy, which demonstrates insufficient bonding between the Ni interlayer and the 4J29 Kovar alloy. Apart from the terrace, some dimples were formed at the bonded area, which was a nickel solid solution with a composition of $10.78 \mathrm{wt}$ \% $\mathrm{Fe}, 16.17 \mathrm{wt}$. $\% \mathrm{Co}$, and $73.05 \mathrm{wt}$. \% Ni. Figure $10 \mathrm{~b}$ shows that, when temperature increased to $900{ }^{\circ} \mathrm{C}$, the area of the terrace sharply decreased, and dimples increased, which significantly promoted the increase in tensile strength. Figure 10c shows a typically ductile fracture of the joint failed at the 4J29 side, which means an excellent bond was achieved at the interface. On applying axial force on the samples, the deformation of the remnant $\mathrm{Ni}$ interlayer was restricted by a mechanical constraint formed by the relatively non-deforming $316 \mathrm{~L}$ and $4 \mathrm{~J} 29$, which caused a state of triaxial stresses that decreased the effective stress on the remnant Ni interlayer [16]. This resulted in the joint failure at the 4J29 side.
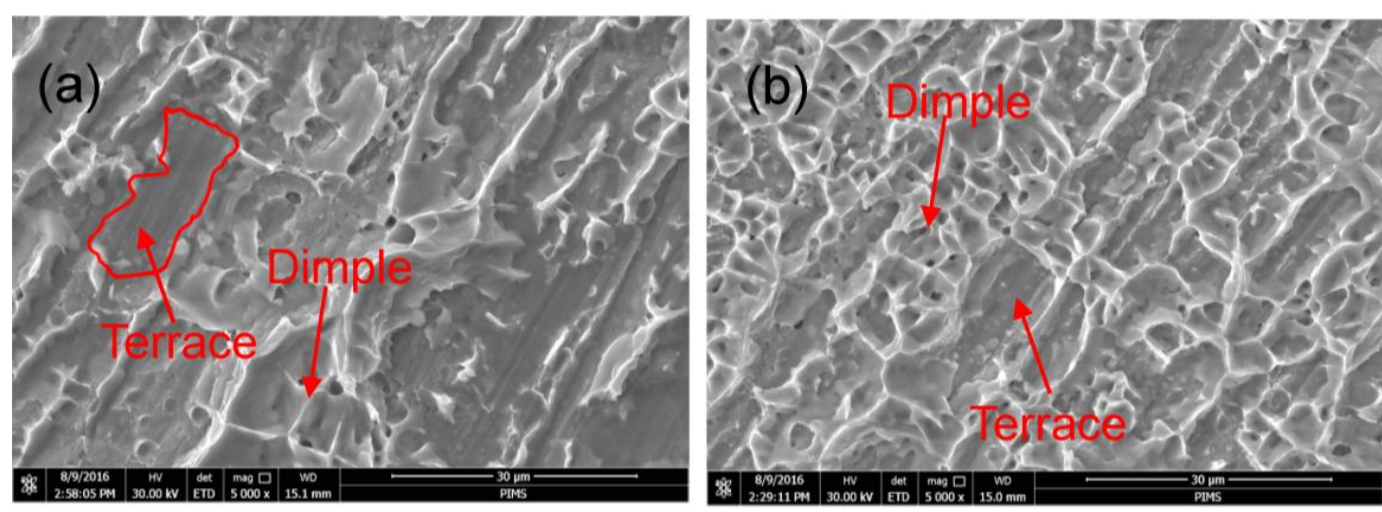

Figure 10. Cont. 


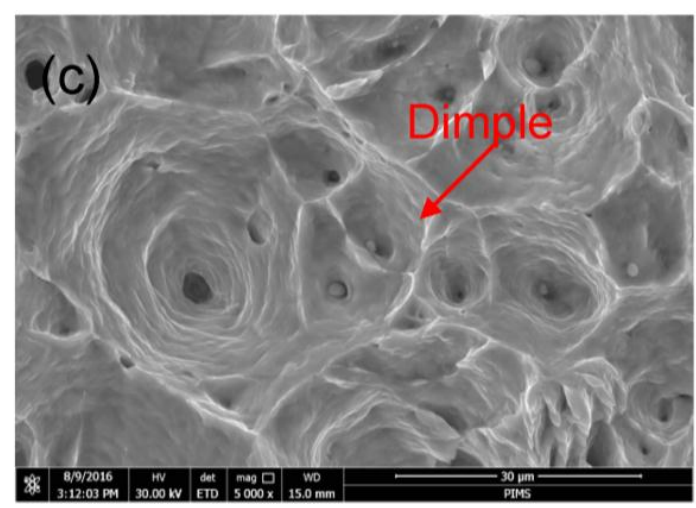

Figure 10. Fracture morphology analysis of diffusion-bonded joints at (a) $850{ }^{\circ} \mathrm{C},(\mathbf{b}) 900{ }^{\circ} \mathrm{C}$, and (c) $950{ }^{\circ} \mathrm{C}$ for $120 \mathrm{~min}$.

\section{Conclusions}

The diffusion bonding of 316L stainless steel and 4J29 Kovar alloys with nickel as an interlayer was carried out in vacuum in a temperature range of $850-950{ }^{\circ} \mathrm{C}$ for $120 \mathrm{~min}$ and at $900{ }^{\circ} \mathrm{C}$ with a bonding time of $120 \mathrm{~min}, 180 \mathrm{~min}$, and $240 \mathrm{~min}$ under $2.5 \mathrm{~T}$ (34.66 MPa) uniaxial pressure, which was applied along the longitudinal direction of the specimen.

1. The Ni interlayer can serve as an effective diffusion barrier for the bonding of stainless steel (316L) and the Kovar alloy (4J29). The composition of the joints was 316L/Ni s.s (Fe-Cr-Ni)/remnant $\mathrm{Ni} / \mathrm{Ni}$ s.s $(\mathrm{Fe}-\mathrm{Co}-\mathrm{Ni}) / 4 \mathrm{~J} 29$.

2. Growth of the diffusion layer was determined with the diffusion coefficient and activation energy, and the activation energy for the diffusion of $\mathrm{Ni}$ into $316 \mathrm{~L}$ and $4 \mathrm{~J} 29$ is $173.68 \mathrm{~kJ} / \mathrm{mol}$ and $133.27 \mathrm{~kJ} / \mathrm{mol}$, respectively.

3. At lower bonding temperatures and times, fracture takes place at the interface of the Ni-4J29 side due to insufficient bonding. After the width of the nickel solid solution (Fe-Co-Ni) increased, failure located at the $4 \mathrm{~J} 29$ side and the fracture surface indicated a ductile nature. The highest tensile strength of $504.91 \mathrm{MPa}$ with an elongation of $38.75 \%$ was obtained at $900{ }^{\circ} \mathrm{C}$ for $240 \mathrm{~min}$.

Acknowledgments: This work was supported by National Natural Science Foundation of China (No. 51201143), Fundamental Research Funds for the Central Universities (No. 2682015CX001), the China Postdoctoral Science Foundation (No. 2015M570794), the Key Laboratory of Infrared Imaging Materials and Detectors, Shanghai Institute of Technical Physics, Chinese Academy of Sciences (No. IIMDKFJJ-14-04), the Sichuan Science and Technology Support Program (No. 2016FZ0079), and R \& D Projects Funding from the Research Council of Norway (No. 263875/H30).

Author Contributions: Tingfeng Song implemented and conducted the diffusion bonding experiments and characterized the interfaces. Xiaosong Jiang and Zhenyi Shao analyzed and discussed the results. All authors participated in the design of the experiments and cooperated in the writing of this paper.

Conflicts of Interest: The authors declare no conflict of interest.

\section{References}

1. Alejandro, H.; Jorge, M.; Ashley, R.; Pedro, F.; Peter, H.; Lawrence, E.M.; Ryan, B.W. Joining of Inconel 718 and 316 Stainless Steel using electron beam melting additive manufacturing technology. Mater. Des. 2016, 94, $17-27$.

2. Casalino, G.; Campanelli, S.L.; Ludovico, A.D. Laser-arc hybrid welding of wrought to selective laser molten stainless steel. Int. J. Adv. Manuf. Technol. 2013, 68, 209-216. [CrossRef]

3. Chen, Y.C.; Tseng, K.H.; Wang, H.C. Small-scale projection lap-joint welding of Kovar alloy and SPCC steel. J. Chin. Inst. Eng. 2012, 35, 211-218. [CrossRef]

4. Zhu, W.W.; Chen, J.C.; Jiang, C.H. Effects of Ti thickness on microstructure and mechanical properties of alumina-Kovar joints brazed with Ag-Pd/Ti filler. Ceram. Int. 2014, 40, 5699-5705. [CrossRef] 
5. Wei, J.H.; Deng, B.H.; Gao, X.Q. Interface structure characterization of Fe36Ni alloy with ultrasonic soldering. J. Alloy. Compd. 2013, 576, 386-392. [CrossRef]

6. Baghjari, S.H.; Akbari, M.S. Experimental investigation on dissimilar pulsed Nd:YAG laser welding of AISI 420 stainless steel to Kovar alloy. Mater. Des. 2014, 57, 128-134. [CrossRef]

7. Akbari, M.S.; Sufizadeh, A.R. Metallurgical investigations of pulsed Nd:YAG laser welding of AISI 321 and AISI 630 stainless steels. Mater. Des. 2009, 30, 3150-3157. [CrossRef]

8. Rossini, M.; Spena, P.R.; Cortese, L.; Matteis, P.; Firrao, D. Investigation on dissimilar laser welding of advanced high strength steel sheets for the automotive industry. Mater. Sci. Eng. A 2015, 628, 288-296. [CrossRef]

9. Casalino, G.; Mortello, M.; Peyre, P. Yb-YAG laser offset welding of AA5754 and T40 butt joint. J. Mater. Process. Technol. 2015, 223, 139-149. [CrossRef]

10. Mai, T.A.; Spowage, A.C. Characterization of dissimilar joints in laser welding of steel-Kovar, copper-steel and copper-aluminum. Mater. Sci. Eng. A 2004, 374, 224-233. [CrossRef]

11. Nekouie, E.M.; Coupland, J.; Marimuthu, S. Microstructure and mechanical properties of a laser welded low carbon-stainless steel joint. J. Mater. Process. Technol. 2014, 214, 2941-2948.

12. Wu, W.Y.; Hu, S.S.; Shen, J.Q. Microstructure, mechanical properties and corrosion behavior of laser welded dissimilar joints between ferritic stainless steel and carbon steel. Mater. Des. 2015, 65, 855-861. [CrossRef]

13. Verena, W.; Bernhard, D.; Silvia, H.; Michael, R. Investigations of dissimilar welds of the high temperature steels P91 and PM2000. Fus. Eng. Des. 2013, 88, 2539-2542.

14. Wang, T.; Zhang, B.G.; Chen, G.Q.; Feng, J.C.; Tang, Q. Electron beam welding of Ti-15-3 titanium alloy to 304 stainless steel with copper interlayer sheet. Trans. Nonferr. Met. Soc. China 2010, 20, 1829-1834. [CrossRef]

15. Yuan, X.J.; Tang, K.L.; Deng, Y.Q.; Luo, J.; Sheng, G.M. Impulse pressuring diffusion bonding of a copper alloy to a stainless steel with/without a pure nickel interlayer. Mater. Des. 2013, 52, 359-366. [CrossRef]

16. Deng, Y.Q.; Sheng, G.M.; Xu, C. Evaluation of the microstructure and mechanical properties of diffusion bonded joints of titanium to stainless steel with a pure silver interlayer. Mater. Des. 2013, 46, 84-87. [CrossRef]

17. Wang, J.D.; He, X.Q.; Li, X.P.; En, Y.F. Hermetic Packaging of Kovar Alloy and Low-carbon Steel Structure in Hybrid Integrated Circuit (HIC) System Using Parallel Seam Welding Process. In Proceedings of the 15th International Conference on Electronic Packaging Technology, Chengdu, China, 12-15 August 2014.

18. Sathiskumar, J.; Torsten, S.; Davies, H.M.; Eggert, D.R.; Brown, S.G.R. Localized microstructural characterization of a dissimilar metal electron beam weld joint from an aerospace component. Mater. Des. 2016, 90, 101-114.

19. Madhusudhan, R.G.; Venkata, R.P. Role of nickel as an interlayer in dissimilar metal friction welding of maraging steel to low alloy steel. J. Mater. Process. Technol. 2012, 212, 66-77. [CrossRef]

20. Sam, S.; Kundu, S.; Chatterjee, S. Diffusion bonding of titanium alloy to micro-duplex stainless steel using a nickel alloy interlayer: Interface microstructure and strength properties. Mater. Des. 2012, 40, 237-244. [CrossRef]

21. Kundu, S.; Sam, S.; Mishra, B.; Chatterjee, S. Diffusion bonding of microduplex stainless steel and Ti alloy with and without interlayer: Interface microstructure and strength properties. Metall. Mater. Trans. A 2014, 45, 371-383. [CrossRef]

22. Kundu, S.; Sam, S.; Chatterjee, S. Interface microstructure and strength properties of Ti-6Al-4V and microduplex stainless steel diffusion bonded joints. Mater. Des. 2011, 32, 2997-3003. [CrossRef]

23. Sun, J.C. Investigation of Surface Nanocrystallinzation and Alloying of Commercial Iron and Diffusion Behavior. Ph.D. Thesis, Chongqing University, Chongqing, China, March 2012.

24. Vigraman, T.; Ravindran, D.; Narayanasamy, R. Effect of phase transformation and intermetallic compounds on the microstructure and tensile strength properties of diffusion-bonded joints between Ti-6Al-4V and AISI304L. Mater. Des. 2012, 36, 714-727. [CrossRef]

(C) 2016 by the authors; licensee MDPI, Basel, Switzerland. This article is an open access article distributed under the terms and conditions of the Creative Commons Attribution (CC-BY) license (http://creativecommons.org/licenses/by/4.0/). 